\title{
A TEORIA DA COMPLEXIDADE E A EDUCAÇÃO EXPERIENCIAL AO AR LIVRE: UM OLHAR À LUZ DA EDUCAÇÃO AMBIENTAL
}

\section{THE COMPLEX THEORY AND THE OUTDOOR EXPERIENTIAL EDUCATION: A LOOK INTO THE LIGHT OF ENVIRONMENTAL EDUCATION}

\author{
MARIANO, Erich de Freitas ${ }^{1}$
}

\begin{abstract}
RESUMO
O pensamento complexo defende que a contextualização do conhecimento deve ser priorizada e a educação experiencial define que as experiências já vividas pelos alunos e a reflexão das experiências que foram mediadas pelo educador também fundamentam a construção do saber. A relação entre a ação/experiência e suas consequências e reflexões, ou seja, sua contextualização, é o que proporciona uma aprendizagem significativa. A educação pela aventura utiliza ferramentas que recontextualizam o conhecimento e reveem a relação do ser humano com a natureza por uma ótica hologramática. Consideram a interpretação complexa da realidade e, por fim, trabalham com as causas e efeitos dos problemas ambientais.
\end{abstract}

PalaVRAS-Chave: Contextualização na educação; Edgar Morin; Educação ao ar livre; Educação pela aventura; Jhon Dewey.

\begin{abstract}
Complex theory holds that the contextualization of knowledge must be prioritized and experiential education defines that the experiences already lived by the students and the reflection of the experiences that were mediated by the educator justify the construction of knowledge. The relation between the action/experience and its consequences and reflections, the contextualization, is what provides meaningful learning. Adventure education uses tools that recontextualize knowledge and review the relationship of the human being with nature through a hologramatic perspective. They consider the complex interpretation of reality and finally work with the causes and effects of environmental problems.
\end{abstract}

KeYWORDS: Context in education; Edgar Morin; Outdoor education; Adventure education; Jhon Dewey.

\section{INTRODUÇÃO}

A capacitação e a formação dos docentes em educação ambiental são fundamentadas por diferentes abordagens ou enfoques teóricos. Essa multiplicidade de abordagens podem indicar tentativas de mudanças nos paradigmas vigentes e na interpretação da realidade atual (SAHEB; RODRIGUES, 2017). Os novos paradigmas tendem a revolucionar a ciência ao buscar responder os problemas até então não

\footnotetext{
${ }^{1}$ Universidade Federal de Campina Grande (UFCG). Patos, PB, Brasil. ORCID: https://orcid.org/00000002-7863-4092 e-mail: efmariano.ufcg@gmail.com
} 
conseguidos e, nessa busca de novos paradigmas, o pensamento complexo proposto por Edgar Morin tem sido usado nas discussões sobre as questões ambientais (AUGUSTO; LAMBERTUCCI; SANTANA, 2012).

MORIN (2007, p. 20-22) afirma que o conhecimento só é pertinente quando o situamos em seu contexto, e se possível no conjunto globalizado. Em seus textos o autor chama esse conhecimento de "complexo", não por ser complicado, mas por requerer um pensamento que capte fenômenos multidimensionais e inter-relacionais. Um pensamento que versa sobre a forma indissociável do todo e de abordagens multi e transdisciplinares para a construção do conhecimento. É a partir dessa observação que mesclamos as ideias de DEWEY (1986), as quais argumentam a favor do valor da experiência no processo educativo. Experiências essas que não ficam estagnadas, mas passam por um processo de reflexão, generalização e só então aplicação do aprendido em novos contextos (KOLB, 1984).

As relações estabelecidas entre a ação/experiência e suas consequências, ou seja, sua contextualização, é o que proporciona a aprendizagem (PALAVAN; CICEK; ATABAY, 2016). Desta forma, indivíduo aprende por meio da observação, intuição, reflexão e da relação com os demais membros do círculo social ao qual está inserido.

Uma das formas de se trabalhar com o processo educativo é através de ferramentas ao ar livre, que de forma geral visam potencializar o ensino-aprendizagem (MARIANO; LIMA, 2019). Na literatura não existe uma definição universal para conceituá-la, então, pode-se considerar como educação ao ar livre todas aquelas que se realizam fora da sala de aula, embora não obrigatoriamente realizada em ambiente natural (MARIANO, 2017). Ela se constitui de uma vivência educacional que faz uso de desafios presentes em áreas naturais ou urbanas como metodologia educativa.

Estudos que abordam o uso da experiência em atividades ao ar livre na educação ambiental mostraram que a capacidade de compreensão de assuntos ligados ao conhecimento ambiental, tais como ecologia, geologia e conservação foi melhorada (EICK, 2012; KOSSACK; BOGNER, 2012; NEDOVIC; MORRISSEY, 2013). Outros autores também relatam o desenvolvimento de uma relação mais próxima com o ambiente quando há o que podemos chamar de uma "interação guiada" em ambientes ao ar livre, no qual um educador/mediador guia as reflexões após a experiência (e.g. BEHRENDT; FRANKLIN, 2014; MEICHTRY; SMITH, 2007; SHEPARDSON et al., 2007).

Fora do Brasil, em países como Estados Unidos, Suécia e Nova Zelândia, as práticas de educação ao ar livre já encontram-se bem estabelecidas, inclusive com várias pesquisas relacionadas publicadas desde as primeiras décadas do século XX, porém esse conhecimento aqui ainda é incipiente (MARIANO, 2017). Contudo, nos últimos anos estudos que visam o emprego de práticas de educação experiencial ao ar livre na educação ambiental vem sendo desenvolvidos (e.g. MARIANO, 2016a, 2016b, 2016c, RODRIGUES; MARIANO, 2016 , MARIANO, 2017, CAVASINI; TEIXEIRA; PETERSEN, 2018, MARIANO; LIMA, 2019).

A proposta do presente estudo é fazer a ligação dos conceitos da teoria da complexidade, propostos por Edgar Morin e a questões levantadas pelo aprendizado experiencial ao ar livre e a educação pela aventura. 
DOI: $10.12957 /$ e-mosaicos.2020.43267

\title{
Pensamento Complexo e a educaÇão ambiental
}

Em seu artigo intitulado "Education as life", Lucie Sauvé (2017) faz algumas perguntas importantes ao leitor:

\begin{abstract}
"How can schools invite, prepare, and accompany youth to take part in the current ecosocial transformation movement? How can education value young peoples' creative force and respond to their quest for meaning and desire for action?" (SAUVÉ, 2017, p. 115).
\end{abstract}

Uma das respostas a esses questionamentos estaria na necessidade dos jovens em receber um suporte para que eles descubram a arte e a paixão em se criar uma cidadania ecologicamente ativa (HAYWARD, 2012 p. 16). Esse suporte pode ser dado através do aprendizado colaborativo e da construção de significados (DEWEY, 1959). Aprender a partir da tradução e reconstrução das experiências é aprender usando o "como para saber" e esses são elementos essenciais no processo de transformação da educação (MORIN, 2015).

A transformação no sistema educacional proposta por Morin aponta a dimensão ecológica na identidade humana como um dos princípios fundamentais a ser considerado (MORIN, 2015). E é a partir desse aspecto que a educação ambiental se enquadra. Nela são trabalhadas as três esferas de interação (com nós mesmos, com outros humanos e a educação ecológica), que são bases para o desenvolvimento pessoal e social (SAUVÉ, 2017). Essas interações são formadoras do humano porque o ambiente forma, deforma e nos transforma na medida em que nós o formamos, deformamos e o transformamos (COTTEREAU, 1999 apud SAUVÉ, 2017).

A auto-eco-organização, termo cunhado por (MORIN, 2007b) que expressa a indissociabilidade entre o sujeito e mundo, expressa o pensamento supracitado de Cottereau. Esse pensamento é refletido na instrumentalização do conhecimento pelos indivíduos, a qual é baseada em princípios éticos, de cidadania e solidariedade e seguem as regras impostas pela sociedade na qual o indivíduo está inserido (MORIN, 2007a). Para tanto, o processo pedagógico aplicado na educação ambiental deve ser multidimensional e interdisciplinar, indo além da disciplinaridade dada pela divisão do conhecimento (MORALES, 2012).

Pensar em multidimensionalidade no conhecimento ambiental é admitir a confluência entre a biosfera e o sistema social e reformular a relação homem-natureza, é repensar a relação de dominância desenvolvida por um paradigma de simplicidade e de segregação (PENA-VEGA, 2010). A complexidade ambiental é fruto da mescla entre natureza, tecnologia e cultura, vai além do conhecimento do sere se abre para um conhecimento da vida (LEFF, 2009).

Sob o olhar da complexidade, formar educadores ambientais exige vencer a fragmentação do conhecimento e a ciência determinista, bem como apresentar uma ética no agir e considerar a realidade socioambiental em que vivemos (SAHEB; RODRIGUES, 2017).

É um (não tão) novo paradigma e, desde o final do século XX, a visão cartesiana e a busca de respostas simplistas na educação ambiental vem sendo diminuídas. Esse 
enfrentamento entre a visão cartesiana e o pensamento complexo possibilita uma maior contribuição da educação ambiental na valorização moral e ética da sociedade, promovendo a construção de um sistema social ambientalmente sustentável e socialmente justo (SAHEB; RODRIGUES, 2017).

O pensamento complexo permite que olhemos para a formação dos educadores ambientais e reflitamos sobre seu processo de formação. É preciso rever os conceitos teóricos desse processo para que tenhamos subsídios em fornecer um diálogo aberto e científico entre as várias dimensões do ambiente (social, política, econômica, cultural, ecológica, pedagógica e humana).

A complexidade não deve ser tida como solução aos problemas na formação dos educadores ambientais, mas deve ser usada como uma ferramenta de discussão nesse processo. Ela dá suporte a formação de um conhecimento que vai além da simples compreensão, mas que permite e estimule um processo reflexivo.

\section{EDUCAÇ̃̃o PELA AVENTURA}

A experimentação é a base da aprendizagem vivencial e na educação experiencial os momentos de reflexão são os catalizadores do aprendizado (KOLB, 1984). Apesar de sempre ouvirmos a frase "O que ouço, esqueço; o que vejo, lembro; e o que vivo, aprend $o^{\prime \prime}$ não podemos considerar que qualquer vivência resulta em aprendizagem (PIMENTEL, 2007). É preciso que processos contínuos de ação e reflexão para que os saberes provenientes da experiência sejam apropriados.

Atualmente, um dos métodos que vem sendo utilizados na formação e desenvolvimento pessoal e social é a educação experiencial em ambientes naturais, também conhecida com educação ao ar livre (MARIANO, 2017). Esta prática vem com o objetivo de desenvolver habilidades, atitudes e conhecimentos sobre o mundo em que vivemos, permeando suas atividades na, sobre e para a natureza (FORD, 1986).

Associado ao desenvolvimento de habilidades, podemos destacar que 0 envolvimento e a motivação de crianças e jovens em atividades educativas são potencializados quando estas são realizadas fora da sala de aula, especialmente em ambientes naturais (SENICIATO; CAVASSAN, 2004). Alguns temas que são abordados dentro da biologia podem ser um pouco mais desafiadores, principalmente quando estes conteúdos são abstratos. Por isso, os educadores devem empreender um esforço na tentativa de gerar uma maior motivação e assim alcançar um patamar significativo na aprendizagem do tema (DURÉ; ANDRADE; ABÍLIO, 2018).

Podemos considerar que a educação ao ar livre, começou há milhares de anos, quando os nossos ancestrais estavam sujeitos a aprender como o mundo funcionava e não existiam salas de aula. Na sua definição e forma de atuação atuais, a educação ao ar livre surge no final do século XIX e no início do século XX, quando os primeiros acampamentos e escolas que abordam esta temática aparecem, bem como as primeiras atividades escoteiras com Banden-Powell, em 1907. Mais a frente, em 1941, outro marco significativo surge com a criação do programa Outward Bound, por Kurt Hahn (MARIANO, 2017). 
DOI: $10.12957 / \mathrm{e}-\mathrm{mosaicos} .2020 .43267$

Normalmente, a prática de uso de ambientes naturais como "salas de aula" em atividades de educação ambiental muitas vezes se limita ao emprego de trilhas ecológicas (MARIANO, 2017). No Brasil, a ausência de uma cultura envolvida e engajada com a vida ao ar livre faz com que seu uso como ferramenta de educação incipiente. A quantidade de programas de educação ao ar livre inseridos nos currículos escolares é praticamente nula, e nos Parâmetros Curriculares Nacionais (PCN) sequer existe qualquer menção a essa ferramenta educacional (MARIANO; LIMA, 2019).

O desenvolvimento de uma cultura educacional ao ar livre passa pelo desenvolvimento de uma cultura social ao ar livre. A literatura apresenta inúmeras evidências de que $o$ acesso à vida ao ar livre, especialmente em áreas verdes, melhora o bem-estar e a qualidade de vida das pessoas (ver KORPELA et al., 2014 para uma breve revisão). Especialmente em países tido como desenvolvidos, como Estados Unidos e países da Europa, a população busca por atividades em ambientes naturais de forma mais massiva. Percebemos esse fenômeno ao observar o fluxo de visitação nos parques ecológicos distribuídos em seus territórios e pelo elevado desenvolvimento de práticas como o montanhismo nesses países.

No Brasil percebemos uma busca mais sutil por esses ambientes. Apesar de termos praias amplamente visitadas e das grandes cidades contarem com parques verdes nos quais a população consegue investir um pouco do seu tempo na natureza, de forma geral, a população brasileira não cultiva o consumo por ambientes naturais, principalmente áreas desconectadas da vida na cidade.

Um ponto que pode colaborar para o desenvolvimento do uso de ambientes naturais é a aplicação de atividades sustentáveis (ecológicas e sociais) que gerem renda, tanto para a manutenção dos espaços quanto para as comunidades envolvidas. Entretanto, esse tipo de ação requer extensas políticas de investimento, que demandam muito dinheiro, tempo e boa vontade dos gestores.

Uma alternativa, é o desenvolvimento escolar de um pensamento ambiental. 0 tempo investido em práticas recreacionais e/ou educativa em ambientes naturais promove experiências restauradoras e consequente bem-estar (KORPELA et al., 2014). Desta forma, com a devida capacitação docente para a prática em ambientes naturais serão promovidas não apenas experiências relacionadas ao aprendizado, mas também experiências afetivas em relação ao ambiente. E são essas experiências afetivas que trarão uma cultura social ao ar livre.

O ensino ao ar livre pode ter características locais, típicas de cada região, podendo ser adaptada e ser utilizada em qualquer parte do mundo. Em países como Inglaterra, Canadá, Austrália e Estados Unidos, ambientes naturais são bastante utilizados como recurso pedagógico, principalmente por meio do montanhismo e da canoagem, mas também através de cavalgadas, esqui na neve, trenós puxados por cães, iatismo e outras modalidades de deslocamento pela natureza. Nesses países, há extensa bibliografia sobre os processos educacionais e avaliações de aprendizagem nesses cursos (VIVEIRO; DINIZ, 2009).

Os ambientes educacionais ao ar livre trazem, de forma intrínseca, um caráter de aventura. Os desafios inerentes a cada paisagem e as experiências vivenciadas através deles se transformam em ricos recursos pedagógicos, pois o contato direto 
com o ambiente estimula a curiosidade, aguça os sentidos e possibilita o confronto entre a teoria e a prática (KUNREUTHER; FERRAZ, 2012; MARIANO, 2017). Um outro aspecto, não menos importante, é o favorecimento de um companheirismo resultante da experiência comum entre os sujeitos envolvidos e a sua manutenção no retorno ao ambiente escolar (VIVEIRO; DINIZ, 2009).

De forma geral, podemos considerar que a educação pela aventura é descrita como uma abordagem curricular holística, que apesar de centrada no estudante visa o entendimento do comportamento pessoal por meio da compreensão das interações interpessoais (COSGRIFF, 2000; DYSON; SUTHERLAND, 2005). O contato com atividades ao ar livre e a prática saudável e estimulante da aventura, como as supracitadas em ambientes naturais, criam uma estreita relação com a educação ambiental, a preservação e a conservação do ambiente.

Junto com os desafios inerentes da prática ao ar livre e da aventura vem os riscos. Em toda atividade ao ar livre existem riscos e eles exercem um papel central na educação experiencial (LIDDLE, 1998). É importante pontuar o que consideramos como risco ou perigo. Este último está associado ao imprevisível e devem ser evitados, enquanto riscos tratam de situações previsíveis e controláveis através de atitudes mitigadoras. Evidentemente, o educador que se utiliza da aventura deve, tanto quanto possível, evitar o perigo e transformar situações nas quais haja algum risco e adequálas às diversas condições que influenciam em sua intervenção educacional. A inspeção prévia de uma via de escalada, a redundância na segurança de ancoragens em escaladas em rocha, um bom sistema de gestão de segurança ao longo de uma travessia, são todos exemplos da tentativa de transformar situações potencialmente perigosas em riscos calculados (MARIANO, 2017).

Não se pretende dizer que a educação ao ar livre pela aventura é melhor do que qualquer outra forma de aprendizado em sala de aula, mais enfatizamos o citado em MARIANO; LIMA (2019), no qual é dito que a educação pela aventura é uma ferramenta conjunta de aprimoramento e integração de técnicas de ensino, que permite aos alunos aprenderem com a experiência e poderem alcançar um desenvolvimento pessoal, social e ambiental.

Essa experiência nas relações entre a educação e o ambiente já vem sendo defendida pela pedagogia progressiva desde o início do Século XX (MODESTO; NEPOMUCENO; ARAUJO, 2018). John Dewey, defensor dessa corrente, aponta que essas relações concebem o conhecimento como algo construído pela adaptação ao ambiente que estamos inseridos e que além de ser um processo biológico, é um processo social (DEWEY, 2008). Para o autor, a educação é uma necessidade vital que reconstrói o conhecimento a partir da experimentação e transmissão de nossas reflexões (DEWEY, 1959).

A educação pela aventura promove um aprendizado significativo e experiencial pois exige do sujeito participante interação com o ambiente e conhecimento deste mundo que o cerca (DEWEY, 1959). 
DOI: $10.12957 /$ e-mosaicos.2020.43267

\section{CONSIDERAÇÕES FINAIS ACERCA DA COMPLEXIDADE E A EDUCAÇÃo PELA AVENTURA}

Existem muitos aspectos que permeiam as relações entre as pessoas e o mundo natural e que os educadores ambientais procuram fomentar, tais como o amor pela natureza, conhecimento, atitudes e comportamentos pró-ambientais (KINSLOW; SADLER; NGUYEN, 2018).

Podemos ressaltar que ações pró-ambientais só existem quando há uma integração da identidade pessoal com o ambiente. Por este motivo a abordagem da prática educacional pela aventura deve estar associada a valorização do diálogo e construção do conhecimento a partir da complementaridade. Ideia esta que está intimamente relacionada com as características fundamentais da teoria da complexidade, tais como a caracterização dos fenômenos como sistemas, abordagens hologramáticas para processos de ensino e aprendizagem e a perspectiva dialógica.

Muito da incorporação de ideias pró-ambiente pode ser adquirido a partir da experiência obtida com o aprendizado pela aventura. DILLON et al. (2006) apontam evidências empíricas do ganho no aprendizado em programas experienciais e, mais recentemente, KINSLOW; SADLER; NGUYEN (2018) demostram que experiências ao ar livre promovem um desenvolvimento no pensamento sócio-científico. Esses estudos demonstram que atividades experienciais ao ar livre promovem o incremento nas competências científicas e ambientais dos estudantes. Esses objetivos de aprendizagem são difíceis de serem conquistados e as políticas educacionais devem considerar os benefícios potenciais da educação ambiental trabalhada através da experiência e aventura ao ar livre. Esses resultados favorecem e encorajam educadores ambientais a investirem mais tempo com ações em ambientes naturais.

Podemos perceber que a prática da educação pela aventura utiliza ferramentas que recontextualizam o conhecimento e reveem a relação do ser humano com a natureza por uma ótica hologramática, ou seja, que o homem faz parte da natureza assim como a natureza faz parte de nós. Considera a interpretação complexa da realidade e, por fim, trabalha com as causas e efeitos dos problemas ambientais.

A educação ambiental experiencial ao ar livre, através da aventura, deve desenvolver a criatividade e habilidades inovadoras a partir da aquisição de competências transversais, essenciais ao manejo e entendimento da incerteza da sociedade.

\section{REFERÊNCIAS}

AUGUSTO, A. V. L.; LAMBERTUCCI, H.; SANTANA, L. C. BUSCA DA IDENTIDADE EPISTEMOLÓGICA DA EDUCAÇÃO AMBIENTAL: A CONTRIBUIÇÃO DO PENSAMENTO COMPLEXO DE EDGAR MORIN. REMEA - Revista Eletrônica do Mestrado em Educação Ambiental, v. 16, n. 0, 22 set. 2012. 
DOI: $10.12957 /$ e-mosaicos.2020.43267

BEHRENDT, M.; FRANKLIN, T. A Review of Research on School Field Trips and Their Value in Education. International Journal of Environmental and Science Education, v. 9, n. 3, p. 235-245, 2014.

CAVASINI, R.; TEIXEIRA, A. P. L.; PETERSEN, R. D. DE S. Percepções de professores sobre a Educação Ambiental ao ar livre. Revista Brasileira de Educação Ambiental (RevBEA), v. 13, n. 1, p. 61-75, 2018.

COSGRIFF, M. Walking Our Talk: Adventure Based Learning and Physical Education. Journal of Physical Education, v. 33, n. 2, p. 89-98, 2000.

DEWEY, J. Democracia e educação. São Paulo: Companhia Editora Nacional, 1959.

DEWEY, J. Experience and Education. The Educational Forum, v. 50, n. 3, p. 241252, 30 set. 1986.

DEWEY, J. O desenvolvimento do Pragmatismo Americano. Cognitio-estudos: Revista Eletrônica de Filosofia, v.5, n.2., p. 119-132, 2008.

DILLON, J. et al. The value of outdoor learning: evidence from research in the UK and elsewhere. School Science Review, v. 87, n. 320, p. 107, 2006.

DURÉ, R. C.; ANDRADE, M. J. D.; ABÍLIO, F. J. P. Teaching biology and contextualization of content: which subjects the High School student realize in your daily life? Experiências em ensino de ciências, v. 13, n. 1, p. 259-272, 2018.

DYSON, B.; SUTHERLAND, S. Adventure education in your physical education program. In: LUND, J.; TANNEHILL, D. (Eds.). Standards-based physical education curriculum development. $3^{\circ}$ ed. Burlington: Jones \& Bartelett Learnig, 2005. p. 229254.

EICK, C. J. Use of the Outdoor Classroom and Nature-Study to Support Science and Literacy Learning: A Narrative Case Study of a Third-Grade Classroom. Journal of Science Teacher Education, v. 23, n. 7, p. 789-803, 10 nov. 2012.

FORD, P. Outdoor education: Definition and philosohy. Whashington Dc.: Officer of Educational Research and Improvement, 1986.

HAYWARD, B. Children, Citizenship and Environment. Londres: Routledge, 2012.

KINSLOW, A. T.; SADLER, T. D.; NGUYEN, H. T. Socio-scientific reasoning and environmental literacy in a field-based ecology class Socio-scientific reasoning and environmental literacy in a field-based ecology class. Environmental Education Research, p. 1-23, 2018. 
DOI: $10.12957 /$ e-mosaicos.2020.43267

KOLB, D. Experiential learning. 1. ed. Englewood Cliffs, New Jersey: Prentice Hall, 1984.

KORPELA, K; BORODULIN, K; NEUVONEN, M.; PARONEN, O.; TYVÄINEN, L. Analyzing the mediators between nature-based outdoor recreation and emotional well-being. Journal of Environmental Psychology, v. 37, p. 1-7, 2014.

KOSSACK, A.; BOGNER, F. X. How does a one-day environmental education programme support individual connectedness with nature? Journal of Biological Education, v. 46, n. 3, p. 180-187, 2012.

KUNREUTHER, F. T.; FERRAZ, O. L. Educação ao ar livre pela aventura: o aprendizado de valores morais em expedições à natureza. Educação e Pesquisa: Revista da Faculdade de Educação da Universidade de São Paulo, v. 38, n. 2, p. 437452, 2012.

LEFF, E. Ecologia, capital e cultura: a territorialização da racionalidade ambiental. Petropolis: Vozes, 2009.

LIDDLE, J. Risk management: Walking the tightrope. Journal of Experiential Education, v. 2, n. 2, p. 61-62, 1998.

MARIANO, E. F. Observações sobre a aplicação da educação experiencial ao ar livre na educação ambiental. Anais do III Congresso Nacional de Educação. Anais...Natal: 2016a. Disponível em: <www.conedu.com.br>. Acesso em: 11 abr. 2019

MARIANO, E. F. Potencial para o uso da escalada em rocha como ferramenta de educação ambiental experiencial no sertão da Paraíba. Anais do III Congresso Nacional de Educação. Anais...Natal: 2016b

MARIANO, E. F. A educação experiencial na educação ambiental. Anais do IV Encontro de Montanhistas e Excursionistas de São Carlos. Anais...São Carlos: 2016c

MARIANO, E. F. Educação ar livre e a educação ambiental: o potencial da aventura aplicada ao ensino no sertão da Paraíba. In: SILVA, E. (Ed.). Temas em ecologia e educação ambiental. Rio de Janeiro: Gramma, 2017. p. 19.

MARIANO, E. F.; LIMA, K. F. G. Uma revisão do (não) emprego da educação ambiental experiencial ao ar livre no Brasil. In: OLIVEIRA, A. C. (Ed.). Produção científica e experiencias exitosas na educação brasileira. 1. ed. Ponta Grossa: Atena, 2019.

MEICHTRY, Y.; SMITH, J. The Impact of a Place-Based Professional Development Program on Teachers' Confidence, Attitudes, and Classroom Practices. The Journal of Environmental Education, v. 38, n. 2, p. 15-32, jan. 2007. 
DOI: $10.12957 /$ e-mosaicos.2020.43267

MODESTO, M. A.; NEPOMUCENO, A. L. O.; ARAUJO, M. I. O. Gênese da educação ambiental em John Dewey e em Paulo Freire e as perspectivas atuais: O que há de novo? Revista Tempos e espaços em educação, v.11, n. 01, p. 363-378, 2018.

MORALES, A. G. Formação do profissional educador ambiental: reflexões, possibilidades e constatações. Ponta Grossa: Editora UEPG, 2012.

MORIN, E. Educação e complexidade: Os sete saberes e outros ensaios. 4. ed. São Paulo: Cortez, 2007a.

MORIN, E. Introdução ao pensamento complexo. $3^{\circ}$ ed. Porto Alegre: Editora Sulina, 2007b.

MORIN, E. Ensinar a viver. Porto Alegre: Editora Sulina, 2015.

NEDOVIC, S.; MORRISSEY, A.-M. Calm active and focused: Children's responses to an organic outdoor learning environment. Learning Environments Research, v. 16, n. 2, p. 281-295, 10 jul. 2013.

PALAVAN, O.; CICEK, V.; ATABAY, M. Perspectives of Elementary School Teachers on Outdoor Education. Universal Journal of Educational Research, v. 4, n. 8, p. 18851893, 2016.

PENA-VEGA, A. O despertar ecológico: Edgar Morin e a ecologia complexa. Rio de Janeiro: Garamond, 2010.

PIMENTEL, A. A teoria da aprendizagem experiencial como alicerce de estudos sobre desenvolvimento profissional. Estudos de Psicologia, v. 12, n. 2, p. 159-168, 2007.

RODRIGUES, D. B.; MARIANO, E. F. Educação ambiental experiencial ao ar livre: Uma revisão. Anais do Congresso Nacional de Pesquisa e Ensino de Ciências.

Anais...Campina Grande: 2016

SAHEB, D.; RODRIGUES, D. G. A contribuição da complexidade de Morin para as pesquisas em Educação Ambiental. REMEA - Revista Eletrônica do Mestrado em Educação Ambiental, v. 0, n. 0, p. 191-207, 26 set. 2017.

SAUVÉ, L. Education as Life. In: Post-Sustainability and Environmental Education. Cham: Springer International Publishing, 2017. p. 111-124.

SENICIATO, T.; CAVASSAN, O. Aulas de campo em ambientes naturais e aprendizagem em ciências: um estudo com alunos do ensino fundamental. Ciência \& Educação (Bauru), v. 10, n. 1, p. 133-147, 2004.

SHEPARDSON, D. P. et al. Students' mental models of the environment. Journal of Research in Science Teaching, v. 44, n. 2, p. 327-348, 1 fev. 2007. 
DOI: $10.12957 / \mathrm{e}-\mathrm{mosaicos} .2020 .43267$

VIVEIRO, A. A.; DINIZ, R. E. S. Atividades de campo no ensino das ciências e na educação ambiental: refletindo sobre as potencialidades desta estratégia na prática escolar. Ciência em tela, v. 2, n. 1, p. 1-12, 2009.

Recebido em 10 de junho de 2019 Aceito em 13 de novembro de 2019

A e-Mosaicos Revista Multidisciplinar de Ensino, Pesquisa, Extensão e Cultura do Instituto de Aplicação Fernando Rodrigues da Silveira (CAp-UERJ) está licenciada com uma Licença Creative Commons - Atribuição-NãoComercial 4.0 Internacional.

Os direitos autorais de todos os trabalhos publicados na revista pertencem ao(s) seu(s) autor(es) e coautor(es), com o direito de primeira publicação cedido à e-Mosaicos.

Os artigos publicados são de acesso público, de uso gratuito, com atribuição de autoria obrigatória, para aplicações de finalidade educacional e não-comercial, de acordo com o modelo de licenciamento Creative Commons adotado pela revista. 